\title{
Psychiatric symptoms in patients with focal cortical degeneration
}

\author{
R.M. Lawrence, M.A. Ronca, P. Tyrrell and M.N. Rossor \\ National Hospital for Neurology and Neurosurgery, Queen Square, London WC1N 3BG, UK
}

\begin{abstract}
The psychiatric phenomenology exhibited by a mixed group of patients with focal cortical degeneration (FCD) is described. The diagnosis of FCD was made in the presence of a slowly progressive focal neuropsychological deficit without evidence of infarct or neoplasm. Localized or asymmetric atrophy was present on neuroimaging (CT or MRI) and positron emission tomography demonstrated focal hypometabolism or in those assessed later in the disease an area of maximal hypometabolism which correlated with the neuropsychological deficit. FCD patients exhibited prominent obsessive-compulsive behaviour. Obsessive-compulsive features were often repetitive, stereotyped and bizarre and occurred in association with frontal and left temporal atrophy and hypometabolism and were absent in those with predominant posterior cortical pathology.
\end{abstract}

Keywords: Focal cortical degeneration - Obsessive compulsive behaviour

\section{INTRODUCTION}

The term focal or asymmetric cortical degeneration (FCD) refers to a group of patients with a slowly progressive neuropsychological deficit associated with focal atrophy on an apparent degenerative basis (Caselli and Jack, 1992). Slowly progressive dysphasia is the commonest clinical presentation, and many such patients have been described in which language disturbance has been the only deficit for many years (Mesulam, 1982; Kirshner et al., 1987; Poeck and Luzzati, 1988; Green et al., 1990; Tyrrell et al., 1990a; Mendez and Zander, 1991; Snowden et al., 1992). Less common presentations include progressive limb (De Renzi, 1986; Dick et al., 1989) or orofacial dyspraxia (Tyrrell et al., 1991), prosopagnosia (Tyrrell et al., 1990b) and disturbance of high visual cortical function leading to visual disorientation (Benson et al., 1988). Widespread cognitive impairment usually follows these focal deficits after some years (Poeck and Luzzati, 1988; Benson et al., 1988; Green et al., 1990), although in some patients with progressive dysphasia non-dominant hemisphere function may remain well preserved for many years. This contrasts with Alzheimer's disease (AD) in which a focal presentation, usually memory impairment, is soon followed by widespread cognitive deficits.

The term FCD is used to describe the clinical picture and does not imply any specific neuropathology other than focal atrophy at the macroscopic level. In some patients the characteristic features of Pick's disease (Graff-Radford et al., 1990) or corticobasal degeneration have been described (Lippa et al.,

(C) 1994 Rapid Communications of Oxford Ltd
1991), in some an asymmetric spongiosis is present (Kirshner et al., 1987), whilst others may be associated with non-specific changes. Occasional patients are found to have Alzheimer histopathology and this is the most common finding in patients with visual disorientation and posterior-cortical atrophy.

Positron emission tomography (PET) has linked the presence of focal areas of hypometabolism to these clinical presentations (Chawluck et al., 1986; Tyrrell and Rossor, 1994). Thus left temporal hypometabolism has been found with progressive dysphasia (Chawluck et al., 1986; Tyrrell et al., 1990a), frontal hypometabolism with orofacial dyspraxia (Tyrrell et al., 1991) and right temporal hypometabolism with progressive prosopagnosia (Tyrrell et al., 1990b). In addition, other areas of hypometabolism can be observed as the disease progresses and the cognitive deficits become more widespread.

Whilst the neurological features of these patients are well characterized, much less attention has been paid to their psychiatric symptomatology, even if clinical experience suggests that behavioural abnormalities are present. We describe here the psychiatric symptomatology of a group of patients with FCD seen at the National Hospital for Neurology and Neurosurgery.

\section{METHODS}

Ten subjects (seven males, three females) with ages ranging from 55 to 82 years, referred to the National Hospital for Neurology and Neurosurgery, were in- 
cluded in the study. A diagnosis of FCD was made on the basis of a slowly progressive focal cognitive deficit together with focal or asymmetric atrophy on computed tomography (CT) or magnetic resonance imaging (MRI). Focal hypometabolism was demonstrated by oxygen-15 PET or an area of maximal hypometabolism commensurate with the neuropsychological deficit in those patients assessed later in the disease (Tyrrell et al., 1990a,c). Patients were excluded if there was evidence of vascular disease (Hachinski score greater than 4; Hachinski et al., 1975), intracranial neoplasm or other structural brain abnormalities.

According to the presenting neurological deficits the patients were allocated to one of the following groups:

(1) dysphasia (Cases 1-6);

(2) orofacial dyspraxia (Case 7);

(3) prosopagnosia (Case 8);

(4) visual disorientation (Cases 9 and 10).

The degree of functional impairment was assessed using the Clinical Dementia Rating Scale (CDR; Berg, 1984), which rates impairment on a four-point scale in the following areas: (1) memory, (2) orientation, (3) judgement and problem solving, (4) community affairs, (5) home and hobbies and (6) personal care. Scores ranged from 0.5 to 2 (mean 1.4).

The Present State Examination (PSE; Wing et al., 1974) was used to explore current psychopathology. Given the cognitive impairment present in these subjects, information as to the presence or absence of specific phenomena was obtained from relatives or carers as well as from patients. Information on the onset and course of illness, past medical history, family and personal history was obtained from the patient, the informant and previous medical notes using a semistructured schedule prepared for the purpose. All the FCD patients had undergone comprehensive neuropsychological testing to confirm the presence of focal neuropsychological deficits (Tyrrell et al., 1990a,b,c, 1991). All the interviews were performed between November 1990 and May 1991 by the same investigator (R.M.L.).

\section{CASE SUMMARIES OF FCD PATIENTS WITH OBSESSIVE-COMPULSIVE BEHAVIOUR}

\section{Patient 1}

A 57 year old right handed butcher presented with a 5 year history of behavioural change and progressive dysphasia. The psychiatric phenomenology was dominated by phases of anxiety, irritability and angry outbursts. His mood was intermittently depressed.
He also became increasingly preoccupied with news of world disasters and constantly relayed this information to others. This was his only topic of conversation and he became irritable and anxious if prevented from attending to the news or talking about them. $\mathrm{He}$ had become unpredictable and his behaviour was socially inappropriate. $\mathrm{He}$ often urinated out of the window and on one occasion he flung himself out of a second floor window, sustaining injuries but denying suicidal intentions.

His CT scan was normal, but bilateral frontal hypometabolism was demonstrated by PET.

\section{Patient 2}

A 75 year old right-handed retired maintenance engineer exhibited behavioural changes for the first time at the age of 70 , when he gradually lost his ability to exercise appropriate judgement in family, social and financial matters. Progressive dysphasia, with repetitive and disjointed speech, was the presenting neurological symptom. He became mildly forgetful at a later stage.

At the beginning of his illness he had phases of irritability accompanied by ideas of persecution. These alternated with periods of clear elation which had come to dominate the picture at the time of the study. He exhibited pressure of speech which was by then dysphasic, circumlocutory and perseverative. Grandiose delusions were also noticed. He believed that he was a member of the House of Lords and often reminisced about attending royal garden parties. He had little insight into his disability and insisted on organizing the family finances.

He developed an excessive concern about washing up dishes, something he insisted on doing in a stereotyped, ritualistic manner several times a day. $\mathrm{He}$ also insisted on clearing the table at the end of each course to the annoyance of his family. Attempts to keep him away from the kitchen and to prevent these rituals provoked a great deal of anxiety and irritability.

Enlargement of the ventricular system, predominantly left sided, with wide cortical sulci over the left temporal lobe were seen on CT and an area of hypometabolism over the left fronto-temporal region with PET.

\section{Patient 3}

A 56 year old right-handed architect had retired from work at the age of 50 because of progressive speech impairment accompanied by difficulty in reading, writing and performing calculations. Some memory difficulties were also present at the time of the study. From the beginning of the illness his mood 
was mildly elated with phases of anxiety and his behaviour was often embarrassing because of inappropriate jocularity. He became more elated as his illness progressed, his libido was reduced and his appetite markedly increased.

An early behavioural change was his insistence on meticulously tidying up everything in the house. $\mathrm{He}$ would repeatedly line up cutlery in a bizarre, stereotyped fashion after having taken it away from his guests half way through dinner. He devised time tables for his cat to go in and out of the house and enforced them rigidly. He insisted in carrying an umbrella everywhere and became anxious and irritable if these rituals were interfered with. He could not provide a rational explanation for his bizarre behaviour.

His CT scan showed left fronto-temporal atrophy with marked hypometabolism in the same cortical regions on PET.

\section{Patient 4 (Case 3, Tyrrell et al., 1990a)}

A 74 year old right-handed retired domestic science teacher presented with a 6 year history of progressive dysphasia, behavioural change and memory problems. By the time of the study she was almost completely mute and had been living in a nursing home for the past 12 months.

Early in the course of her illness she had become excessively cheerful, lacking insight into her limitations. While in the nursing home, she developed an overriding interest in the belongings of another resident she shared a room with. She took to tidying her personal possessions and making her bed over and over again, despite the nursing staff's attempts to dissuade her.

Her CT scan showed left ventricular enlargement and left temporal sulcal widening. PET scan performed 18 months after onset of symptoms of language disturbance revealed left temporoparietal hypometabolism.

\section{Patient 5}

A 55 year old right-handed manager of a decorating business presented with word finding difficulties and poor concentration. These symptoms had developed very insidiously since the age of 40 . A change in personality had also been observed by his relatives. Previously a confident and outgoing person, he had become apathetic and indifferent and at times short tempered and irritable. Depressive symptoms of considerable severity were also noticed with early morning waking, diurnal mood variation, delusions of guilt and recurrent delusions of persecution involving his family, friends and physicians. He preserved some insight into his illness and often wished to die, but he never made any suicidal attempts. His appetite as well as his libido were markedly diminished. Antidepressant medication failed to alleviate the symptoms.

He became extremely preoccupied about paying his bills and spent hours every day repeatedly running through them. He also visited the cashpoint several times a day to check his bank account. Suggestions that this behaviour was unreasonable or attempts to change his routine met with great anxiety and angry outbursts.

His CT scan showed left ventricular enlargement and left temporal sulcal widening. Left temporal hypometabolism was seen with PET.

Patient 6 (Case 6, Tyrrell et al., 1990a)

A 69 year old right-handed retired stock exchange employee presented with a 9 year history of progressive speech difficulties, poor concentration and memory difficulties. By the time of the study he had become completely mute apart from highpitched grunts. From the onset of his illness his mood became tense and irritable. This evolved into a picture where phases of extreme withdrawal alternated with dramatic episodes of excitement and unprovoked anger. During these outbursts he would shout and fling objects around. His sleep was disturbed and he lost weight whilst maintaining a good appetite. He had lost his libido from the beginning of the illness.

Between 1984 and 1988, when travelling by train he insisted on standing by the toilet door and became very agitated if this was not possible or his wife attempted to take him away. He also insisted on locking up all doors in the house at five o'clock in the evening, locking his wife in the garage on one occasion. He could not be dissuaded from performing these rituals and, if antagonized, became angry and agitated. He was unable to explain his behaviour.

His CT scan showed left ventricular enlargement and sulcal widening over the left temporal lobe. Widespread asymmetric hypometabolism was demonstrated by PET, affecting frontal, temporal and parietal lobes with the maximal deficit in left temporal lobe.

\section{Patient 7 (Case 1, Tyrrell et al., 1991)}

A 66 year old right-handed widow and ex-shop owner presented with a $4 \frac{1}{2}$ year history of progressive orofacial dyspraxia and language impairment with slowly progressive memory deterioration. She had developed a depressive syndrome with persecutory delusions, 
TABLE I. Focal cortical degenerations

\begin{tabular}{|c|c|c|c|c|}
\hline Subject/sex & Age & $\begin{array}{l}\text { Age of } \\
\text { onset }\end{array}$ & PET hypometabolism & Psychopathology \\
\hline \multicolumn{5}{|l|}{ (1) Dysphasia } \\
\hline $1 / M$ & 57 & 52 & Bilateral, frontal. & $\begin{array}{l}\text { Depressed mood, agitation, lack of social aware- } \\
\text { ness, OCB }\end{array}$ \\
\hline $2 / M$ & 75 & 70 & Left fronto-temporal & $\begin{array}{l}\text { Elation, pressure of speech, grandiose delu- } \\
\text { sions, OCB }\end{array}$ \\
\hline $3 / M$ & 56 & 50 & Left fronto-temporal & Elation, OCB \\
\hline $4 / F$ & 74 & 68 & Left fronto-temporal & Elation, OCB \\
\hline $5 / M$ & 55 & 40 & Left fronto-temporal & $\begin{array}{l}\text { Depressed mood, early waking, DMV, delusion } \\
\text { of guilt, persecutory delusions, OCB }\end{array}$ \\
\hline $6 / M$ & 69 & 60 & Left fronto-temporal & Withdrawal, outbursts of temper, OCB \\
\hline \multicolumn{5}{|c|}{ (2) Orofacial dyspraxia } \\
\hline $7 / F$ & 66 & 62 & Left fronto-temporal & $\begin{array}{l}\text { Depressed mood, agitation, persecutory delu- } \\
\text { sions, OCB }\end{array}$ \\
\hline \multicolumn{5}{|c|}{ (3) Prosopagnosia } \\
\hline $8 / \mathrm{M}$ & 82 & 67 & Right temporal, left temporal & Anxiety, OCB \\
\hline \multicolumn{5}{|c|}{ (4) Visual disorientation } \\
\hline $9 / M$ & 74 & 66 & Bilateral, occipital & Elation, visual/tactile hallucinations \\
\hline $10 / F$ & 74 & 60 & Bilateral, occipital & $\begin{array}{l}\text { Anxiety, depressed mood, delusions of guilt, } \\
\text { visual/tactile hallucinations }\end{array}$ \\
\hline
\end{tabular}

OCB, obsessive-compulsive behaviour. DMV, diurmal mood variation

accompanied by biological features such as diurnal mood variation, appetite and weight loss. She often felt that life was not worth living but she never attempted suicide. Small doses of antidepressants produced some improvement.

From the beginning of her illness she became excessively friendly and socially disinhibited. She insisted on watching television at particular times, regardless of what was on, often with the sound turned off. If anybody switched the set on at other times or tuned onto a different channel, she became angy and agitated and tried to turn it off. She was unable to explain her behaviour.

The CT scan showed left temporal sulcal widening and ventricular enlargement and the PET scan revealed left fronto-temporal hypometabolism.

Patient 8 (Tyrrell et al., 1990b)

An 82 year old right-handed retired pharmacist presented with a 15 year history of difficulty in recognizing familiar faces. Some years later, he began to experience difficulty in finding words. For the last 2 years prior to the study he had been troubled by insomnia and fluctuating anxiety.

In what he saw as an attempt to halt his memory difficulties, he took to repeating strings of numbers and spent several hours a day or the entire night doing so. Attempts to halt this behaviour resulted in increased anxiety and irritability.
His CT scan showed mild, bilateral ventricular and sulcal widening. Right temporal and a small area of left anterior temporal hypometabolism were observed with PET.

\section{RESULTS}

The demographic and clinical featrues of FCD patients are shown in Table I.

At the time of the study the mean age of FCD patients was 68.2 (range 55-82), the mean duration of illness being 8.7 years.

The onset of symptoms had been insidious and in the majority of cases the initial presenting features had been inappropriate behaviour and fluctuating affective symptoms in the absence of obvious cognitive impairment. Severe depression with mood congruent delusions was reported during the 18 months preceding the study. Four FCD patients (Cases 1, 5, 7 and 10) had experienced these symptoms together with biological shifts (i.e. early waking, anorexia, weight loss, diurnal variation of mood). One FCD patient (Patient 2) had grandiose delusions.

Three FCD cases had a family history of dementia and three others of affective disorder. None of the FCD patients had a previous history of psychiatric illness.

Obsessive-compulsive behaviour was present in eight FCD patients (Patients 1 to 8 ) at some time in 
their illness. Compulsive, repetitive thoughts were often reported even if patients were unable to provide an explanation or elaborate as to the contents. Bizarre, stereotyped routines which provoked anxiety if interrupted were consistently reported by the patients or relatives, who also remarked on the patient's lack of insight. The presence of these features was associated with maximal hypometabolism in the left frontal or fronto-temporal region in six out of eight patients. The remaining two patients had bilateral frontal (Patient 1) or a combination of left frontal and right temporal hypometabolism (Patient 8). The two FCD patients without obsessive-compulsive features (Patients 9 and 10) had posterior cortical atrophy with maximal areas of hypometabolism in the occipital lobes.

The observed patients' lack of insight into different aspects of their psychopathology was beyond the scope of this paper, but was later used as the basis for the development of a structured battery for the assessment of insight. This is described elsewhere.

\section{DISCUSSION}

FCD subjects presented with a fairly wide range of psychiatric disturbance but the salient finding of this study was the frequent occurrence of obsessivecompulsive behaviour in these patients.

The symptoms exhibited by the FCD patients closely resembled those of obsessive-compulsive disorder (OCD), but some important differences were also apparent. Obsessional thoughts were reported less frequently than compulsions, either because they were rarer or because language difficulties or cognitive impairment made them less accessible. On the other hand repetitive actions were very common, but unlike in OCD, our patients did not always recognize the excessiveness or absurdity of their actions or attempt to suppress them. As a result, anxiety was not a feature of the mental state and distress only occurred when these actions were prevented by others.

Obsessive-compulsive symptoms have been described in a variety of neurological disorders where pathology disrupts fronto-subcortical circuits, in particular when lesions are located in the orbitofrontal or anterior cingulate cortices or in the globus pallidus (see Cummings, 1993, for review). Lesions involving the orbitofrontal cortex are in addition associated with personality changes, irritability and emotional lability, whilst pathology in the anterior cingulate tends to cause apathy and lack of responsiveness. In the FCD patients the presence of obsessive-compulsive behaviour together with personality changes and affective lability suggest the involvement of the orbit- ofrontal cortex and its subcortical connections. Obsessive-compulsive symptoms have also been described in AD (Burns et al., 1990) and are likely to result from lesions affecting these same circuits. In addition the presence of persistent depressive symptomatology points towards involvement of the dorsolateral prefrontal cortex and related subcortical structures. The co-existence of behavioural symptoms associated with different lesion sites is to be expected in degenerative conditions such as FCD and AD where pathology is not well localized. The hypometabolism observed in many FCD patients extending to most areas of the frontal lobes is in keeping with the presence of a complex constellation of psychiatric symptoms. The asymmetrical reduction of metabolism affecting preferentially the left frontal region, often extending to the neighbouring temporal area, is in keeping with the dysphasic presentation of many FCD patients and not necessarily associated with the presence of obsessive-compulsive behaviour, more likely to be due to bilateral frontal pathology.

PET findings in primary OCD cannot be strictly compared with those of our study given the presence of gross brain disease in our patients. In primary OCD, hypermetabolism in the orbito-frontal cortex and caudate has been commonly reported (Baxter, 1990), although one study (Martinot et al., 1990) has reported frontal hypometabolism. In OCD, striatal dysfunction may cause secondary cortical disinhibition with increased metabolism, whilst in FCD the primary pathology is likely to be cortical. Interruption of this fronto-subcortical circuit at different levels is likely to cause similar behavioural disturbances (Cummings, 1993), although the primary cortical pathology in FCD patients may account for the lack of insight and anxiety and the rarity of obsessional thoughts in our patients.

The methodology of our study is open to criticism which we hope will not detract from the overall value of the study. Dysphasia and other cognitive problems made it necessary to collate information from several sources rather than to rely on the patients' own descriptions. This may have lead us to underestimate the frequency of the more subtle, subjective symptoms such as obsessional thoughts.

Finally, the authors preferred to use descriptive clinical categories based on neurological symptoms rather than diagnostic/disease categories. This particularly applies to the dysphasia group, phenomenologically part of frontal lobe dementias. This choice of terminology was aimed at avoiding neuropathological commitments prior to postmortem. 


\section{Acknowledgements}

The assistance of Dr F. Clegg and Ms K. Blakeley with neuropsychological assessment and $\operatorname{Dr}$ A. Kennedy and Professor R. Frackowiak with PET scans is gratefully acknowledged.

\section{REFERENCES}

Baxter LR (1990) Brain imaging as a tool in establishing a theory of brain pathology in obsessive compulsive disorder. Journal of Clinical Psychiatry, 51(Suppl), 22-25.

Baxter LR, Phelps ME and Mazziotta JC (1987) Local cerebral glucose metabolic rate in obsessive compulsive disorder. Archives of General Psychiatry, 44, 211-218.

Benson DF, Davis RF and Snyder BD (1988) Posterior cortical atrophy. Archives of Neurology, 45, 789-793.

Berg L (1984) Clinical Dementia Rating. British Journal of Psychiatry, 145, 339.

Burns A, Jacoby R and Levy R (1990) Psychiatric phenomena in Alzheimer's disease IV: Disorders of behaviour. British Journal of Psychiatry, 157, 86-94.

Caselli RJ and Jack CR (1992) Asymmetric cortical degeneration. A proposed clinical classification. Archives of Neurology, 49, 770-780.

Chawluck JB, Mesulam MM, Hurtig H, Kushner M, Weintraub S, Saykin A, Rubin N, Alavi A and Reivich M (1986) Slowly progressive aphasia without generalised dementia: studies with Positron Emission Tomography. Annals of Neurology, 19, 68-74.

Cogan DG (1985) Visual disturbance with progressive dementing disease. American Journal of Ophthalmology, 100, 68-72.

Cummings JL (1993) Frontal-subcortical circuits and human behaviour. Archives of Neurology, 50, 873-880.

De Renzi E (1986) Slowly progressive visual agnosia or apraxia without dementia. Cortex, 22, 171-180.

Dick JPR, Snowden J, Northen B, Goulding PJ and Neary D (1989) Slowly progressive aphasia. Behavioural Neurology, 2, 101-114.

Frackowiak RSJ, Pozzilli C, Legg NJ, et al. (1981) Regional cerebral oxygen supply and utilisation in dementia. Brain, 104, 735-758.

Graff-Radford NR, Damasio AR, Hyman BT, Hart MN, Damasio H, Van Hoessen GW and Rezai K (1990) Progressive aphasia in a patient with Pick's disease: a neuropsychological radiologic and anatomic study. $\mathrm{Neu}$ rology, 40, 620-625.

Green J, Morris JC, Sandson J, McKeel DW Jr and Miller JW (1990) Progressive aphasia: a precursor of dementia? Neurology, 40, 423-429.

Hachinski VC, Iliff LD, Zilkha E, DuBoulay GH, McAlistair VL, Marshall J, Ross-Russell RW and Symon L (1975) Cerebral blood flow in dementia. Archives of Neurology, 32, 632-637.

Hollander E, Schiffman E and Cohen B (1990) Signs of central nervous system dysfunction in obsessive compulsive disorder. Archives of General Psychiatry, 47, 27-32.

Hughes CP, Berg L, Danziger WL, Coben LA and Martin RL (1982) A new clinical scale for the staging of dementia. British Journal of Psychiatry, 140, 566-572.

Kirshner HS, Tanrigdag O, Thurman $\mathrm{L}$ and Whetsell WO Jr (1987) Progressive aphasia without dementia: two cases with focal spongiform degeneration. Annals of Neurology, 22(4), 527-532.
Laplane D, Levasseur M, Pillon B, Dubois B, Baulac M, Mazoyer B, Trandinh S, Sette G, Danze F and Baron JC (1989) OCD and other behavioural changes with bilateral basal ganglia lesions: a neuropsychological, magnetic resonance imaging and positron tomography study. Brain, 112, 699-725.

Lippa CF, Cohen R, Smith TW and Drachman DA (1991) Primary progressive aphasia with focal neuronal achromasia. Neurology, 41, 882-886.

Martinot JL, Allilaire JF, Mazoyer BM, Hantouche E, Huret JD, Legaut-Demare F, Deslauriers AG, Hardy P, Pappata S, Baron JC and Syrota A (1990) Obsessivecompulsive disorder: a clinical, neuropsychological and positron emission tomography study. Acta Psychiatrica Scandinavica, 82, 233-242.

McKhann G, Drachmand D, Folstein M, Katzman R, Price D and Stadlan EM (1984) Clinical diagnosis of Alzheimer's disease. Neurology, 34, 939-944.

Mendez MF and Zander BA (1991) Dementia presenting with aphasia. Clinical characteristics. Journal of Neurology, Neurosurgery and Psychiatry, 54, 542-545.

Mesulam MM (1982) Slowly progressive aphasia without generalised dementia. Annals of Neurology, 11, 592-598.

Mesulam MM (1987) Primary progressive aphasia-differentiation from Alzheimer's disease. Annals of Neurology, 22, 533-534.

Nordahl TE, Benkelfat C, Semple WE, Gross M, King AC and Cohen RM (1989) Cerebral glucose metabolic rates in obsessive compulsive disorder. Neuropsychopharmacology, 2(1), 23-28.

Poeck K and Luzzati C (1988) Slowly progressive aphasia in three patients: the problems of accompanying neuropsychological deficit. Brain, 111, 151-168.

Snowden JS, Neary D, Mann DMA, Goulding PJ and Testa HJ (1992) Progressive language disorder due to lobar atrophy. Annals of Neurology, 31, 174-183.

Tyrrell PJ and Rossor MN (1994) Progressive aphasia and other focal syndromes. In: Dementia (Eds A Burns and R Levy), pp. 823-834. Chapman and Hall, London.

Tyrrell PJ, Warrington EKW, Frackowiak RSJ and Rossor MN (1990a) Heterogeneity in progressive aphasia due to focal cortical atrophy. Brain, 113, 1321-1336.

Tyrrell PJ, Warrington EK, Frackowiak RSJ and Rossor MN (1990b) Progressive degeneration of the right temporal lobe studied with Positron Emission Tomography. Journal of Neurology, Neurosurgery and Psychiatry, 53, 1046-1050.

Tyrrell PJ, Sawle GV, Ibanez V, Bloomfield PM, Leenders KL, Frackowiak RSJ and Rossor MN (1990c) Clinical and PET studies in the "extrapyramidal syndrome" of dementia of the Alzheimer type. Archives of Neurology, 47, 1318-1323.

Tyrrell PJ, Kartsounis LD, Frackowiak RSJ, Findley RJ and Rossor MN (1991) Progressive loss of speech output and orofacial dyspraxia associated with frontal lobe hypometabolism. Journal of Neurology, Neurosurgery and Psychiatry, 54, 351-357.

Wing JK, Cooper JE and Sartorius N (1974) Measurement and Classification of Psychiatric Symptoms. Cambridge University Press, Cambridge.

(Received 17 February 1994; accepted as revised 20 October 1994) 


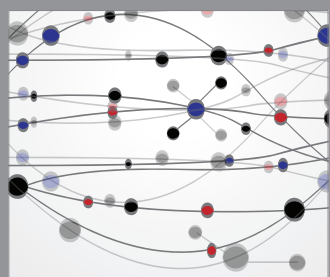

The Scientific World Journal
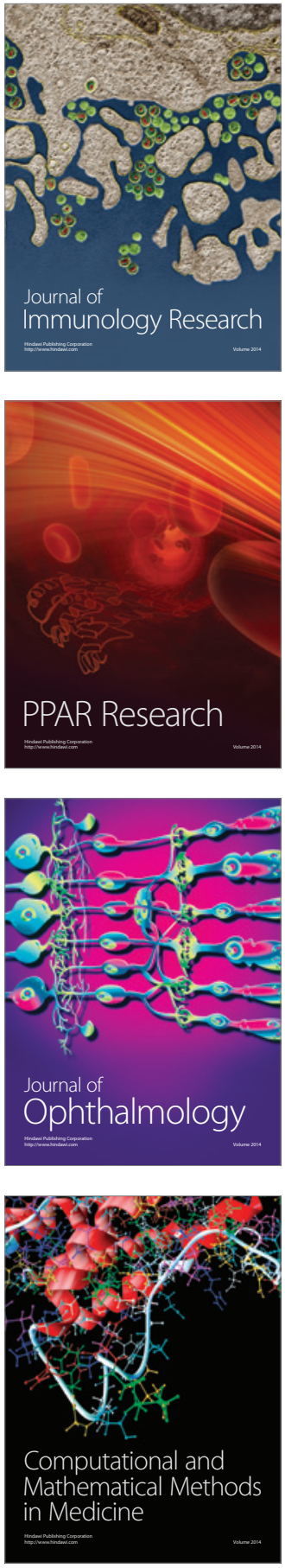

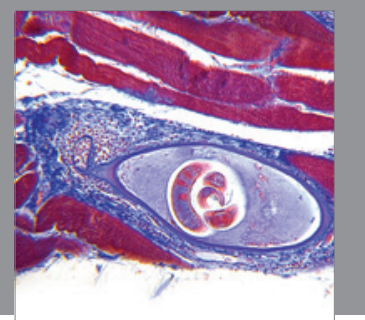

Gastroenterology

Research and Practice
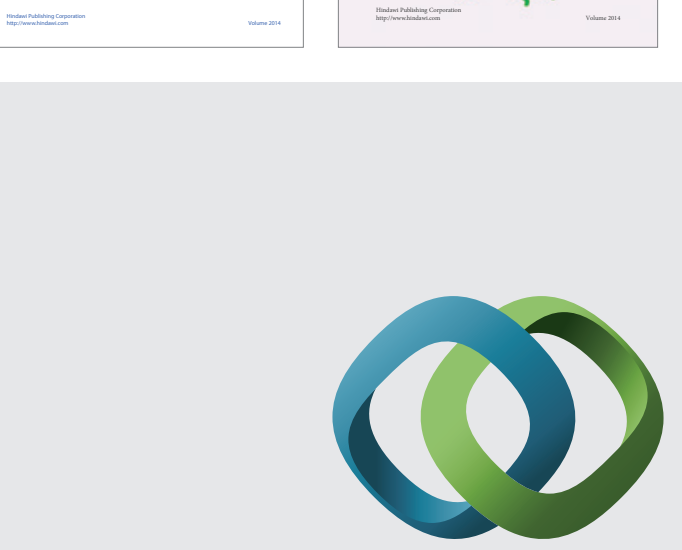

\section{Hindawi}

Submit your manuscripts at

http://www.hindawi.com
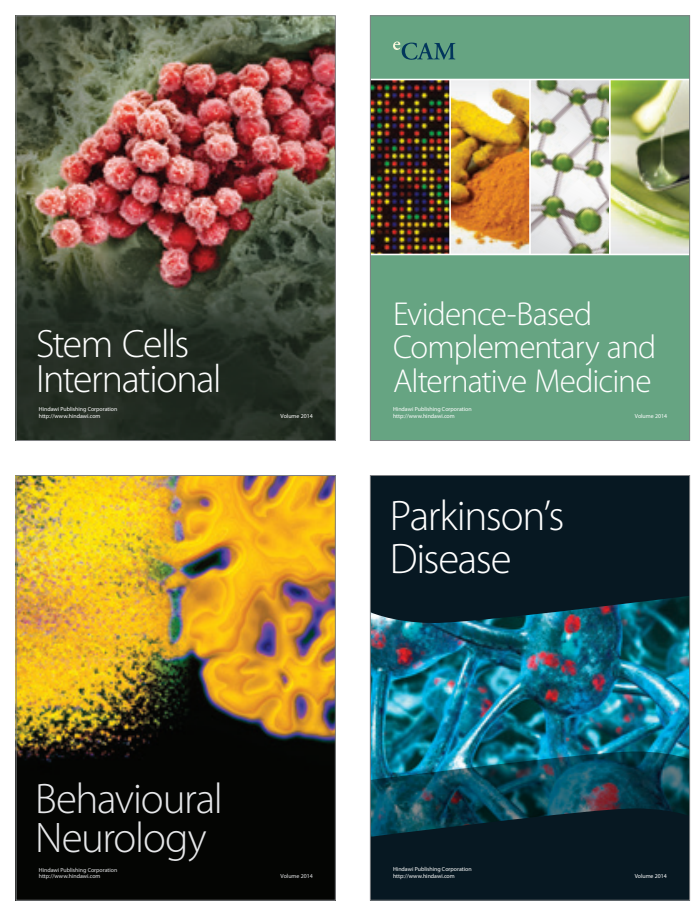

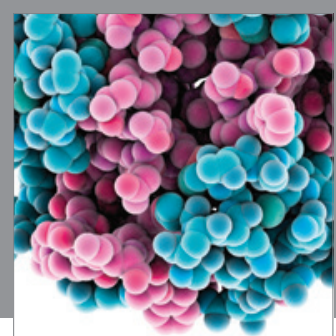

Journal of
Diabetes Research

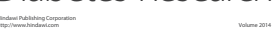

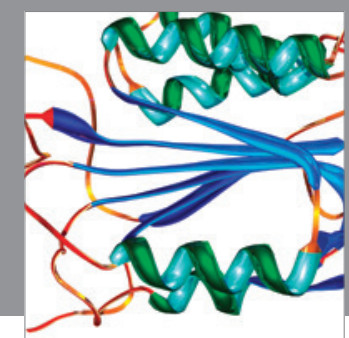

Disease Markers
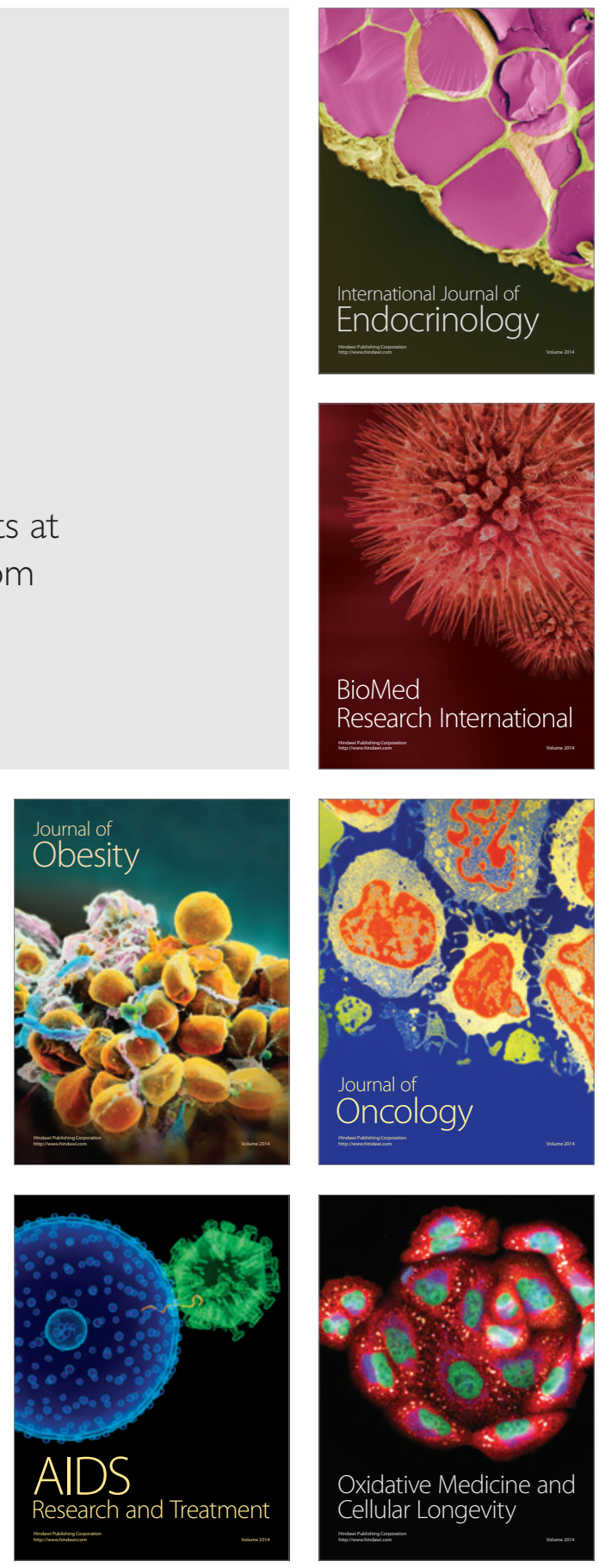